\title{
Pre-COVID-19 pandemic: effects on air quality in the three cities of India using fuzzy MCDM model
}

\author{
S. Suresh ${ }^{1} \cdot$ Rahul Modi $^{2} \cdot$ A. K. Sharma ${ }^{2} \cdot$ S. Arisutha ${ }^{3} \cdot$ Mika Sillanpääa,5,6 $^{4,6}$
}

Received: 15 January 2021 / Accepted: 23 October 2021 / Published online: 29 November 2021

(c) Springer Nature Switzerland AG 2021

\begin{abstract}
Due to urbanization and industrialization pollution level increases. Air pollution directly affects to human health. Air Quality Indices (AQI) method is related to measuring the concentration of different pollutants $\mathrm{PM}_{10}, \mathrm{NO}_{2}, \mathrm{SO}_{2}$ and other pollutants. The fuzzy Logic air quality index calculates in single value of AQI defines limits 0 to 1 . In this study, a comparison of air quality data of three cities was conducted with the help of fuzzy logic algorithm. It used to evaluating Indices through fuzzy multi criteria decision making (MCDM) framework in which linguistic terms of experts opinion and perception, accordingly computing matrix is constructed for sub criteria. There are five linguistic terms used in this framework to create membership functions such as high significant, significant, average significant, low significant and not significant. The three cities, Bangalore, Mysore, and Hubli-Dharwad air quality datas was taken for analysis and evaluating indices during pre-COVID years (2017, 2018, and 2019). The AQI value shows that Bangalore has the highest pollution level while Mysore has the lowest. Using the fuzzy theory, results show that Bangalore and Hubli-Dharwad decrease in pollution level by $-0.074921 \%$ and $-0.04797 \%$. Negative sign shows the decrease pollution level while Mysore increase pollution level by $0.011792 \%$. Overall the results show that AQI of Mysore city is low compared to Bangalore and Hubli-Dharwad. Also, this study reveals air quality disseminated through industrial processes and automobile emissions in India cities during pre-COVID pandemic years.
\end{abstract}

Keywords Air pollution $\cdot$ Air quality index $\cdot$ Fuzzy logic $\cdot$ Linguistic $\cdot$ Membership $\cdot$ Function $\cdot$ Indian cities

S. Suresh

sureshpecchem@gmail.com; sureshs@manit.ac.in

$\triangle$ A. K. Sharma

aksphd2000@yahoo.com

$\triangle$ Mika Sillanpää

mikaetapiosillanpaa@duytan.edu.vn

1 Department of Chemical Engineering, Maulana Azad National Institute of Technology Bhopal, 462003 Madhya Pradesh, India

2 Department of Civil Engineering, Maulana Azad National Institute of Technology Bhopal, 462003 Madhya Pradesh, India

3 Energy Centre, Maulana Azad National Institute of Technology \& Eco-Science and Technology, Bhopal-462 003, Madhya Pradesh, India

4 Institute of Research and Development, Duy Tan University, Da Nang 550000, Vietnam

5 Faculty of Environment and Chemical Engineering, Duy Tan University, Da Nang 550000, Vietnam

6 Department of Chemical Engineering, School of Mining, Metallurgy and Chemical Engineering, University of Johannesburg, P. O. Box 17011, Doornfontein 2028, South Africa

\section{Introduction}

Air quality can be defined as the cleanness of air which is determined by the pollution level. Low levels of air quality and thus high levels of air pollution lead to an increase in public health issues. Air pollution is caused mainly due to different activities such as damages buildings, landmarks, vehicle emission etc. Breathing and other problems in the human body due to air pollutants [1].

As per World Health Organization [2], air pollution is the $13^{\text {th }}$ leading cause of Air pollution is a growing problem in the world today and the WHO ranks air pollution as the $13^{\text {th }}$ leading cause of health problem to all mortality of worldwide mortality. Results of air pollution, nearly 627,000 premature deaths in India [3, 4]. Mehmood et al. [5] reported acute respiratory failure during COVID-19 and other life-threatening diseases [6]. Ricco et al. [7] reported that air quality in the atmosphere significantly improved (mainly $\mathrm{PM}_{10}$ ) during lockdown measures. The high casualties has come all over the world during COVID-19, infectious virus name "SARS-CoV-2 which 
was first traced in China (Wuhan). The dead caused by this COVID-19 day-by-day get increases and preventive measures like national lockdown, social distancing and avoid crowd of people through functions or any others were taken almost all part of the world. As per sources, Brazil, USA UK and others countries were worst-affected with high dead rate [8-11]. In India, first case was reported on January 30, 2020 and found cases were increased. The most affected state by this COVID-19, Maharashtra, Tamil Nadu, Delhi, Gujarat, and all other states are subsequent [12]. However, none of report or research available for preCOVID pandemic situation. Pereira et al. [13] suggested air filter reduces particle concentrations in an orthopaedic operating room.

Balmat et al. [14] described fuzzy set theory which allows solving a lot of problems related to dealing the imprecise and uncertain data in the several applications like engineering, economic, environmental, social, medical, and management. Few of the researchers demonstrated the application of the computing fuzzy logic analyses for the interaction of various air pollutants $[1,15]$. As per the WHO report, by the burning of solid fuels, more than two million premature deaths per year can be attributed to the effects of urban (outdoor / indoor) air pollution. Guerreiro et al. [16] analyzed air quality in Europe from 2002 to 2011. Balmat et al. [14] evaluated the air pollution prevent base on decision-making system on the open sea.

The Air Quality Index (AQI) is basically to design for health protection as well as an indicator of improving the quality of containment air. It indicates a high health risk above 300 level (range is from 1 to 500). On the basis of the impact of pollutants on the health, air quality index is categorized in six-part namely Good, Satisfactory, Moderately polluted, Poor, Very Poor, and Severe. The AQI values and corresponding ambient concentrations (health breakpoints) as well as associated likely health impacts for the identified pollutants. It has also been identified by specific color code (shown in Table 1). Particulate matter $\left(\mathrm{PM}_{10}\right)$ is a mixture of solids and liquid droplets floating in the air. They include dust, dirt, soot, smoke etc. The diameter of these particles is less than or equal to 10 microns. Some particles are emitted directly into the air from various source that are either natural or originated from human activity. $\mathrm{PM}_{10}$ causes health problems, its shortterm exposure (hours and day) can lead to irritating eyes, nose and throat. Nitrogen dioxide and sulfur dioxide comes mainly from motor vehicle exhaust. Yu et al. [17] assessed air quality in China's cities. The pollutants include $\mathrm{SO}_{2}, \mathrm{NO}_{2}$, $\mathrm{PM}_{10}, \mathrm{PM}_{2.5}, \mathrm{CO}$ and $\mathrm{O}_{3}$. They were used a fuzzy synthetic evaluation model which concluded that main sources of air pollution are industrial combustion processes and automobile emissions. Figure 1 shows particulate matter across different cities/towns especially, $\mathrm{PM}_{10}$ levels have increased in 8 other regions across Karnataka [18]. This figure clearly also indicates the importance of present study.

Yang et al. [19] developed a novel hybridization model combining complementary together empirical mode decomposition and an Elman neural network for verifying the pollutants data in two cities (Xi'an and Jinan) of China. The result of the fuzzy comprehensive evaluation shows that $\mathrm{PM}_{10}$ and $\mathrm{PM}_{2.5}$ are present as major pollutants in Xi' an and Jinan cities and also shows that the quality of air in Xi' an city is better than the Jinan city. Chauhan et al. [20] and Singh and Tiong [21] demonstrated the Jhansi and its nearby area are highly affected by the particulate matter in the atmosphere. They found a concentration of $\mathrm{SO}_{2}$ lies between the range of 5.7 to $10.47 \mu \mathrm{g} / \mathrm{m}^{3}$ in the studied area.

Moraga [22] reviewed classical as well as new applications of fuzzy logic. Linguistic Terms are labelled fuzzy sets, usually with a trapezoidal or bell-shaped structure. Debnath et al. [23] studied the effect of a comparative study on the air quality index with different types of air pollutants in a different season. They showed results that air quality index has been increased continuously during the festive period of time because of fireworks uses significantly increased with every year. The Fuzzy multi evaluation model used for developing air pollution composite index for Industries at the State of Gujarat, India [24, 25]. No specific air pollution study available in the literatures for these three cities.
Table 1 Air quality index has been identified by specific color code

\begin{tabular}{lll}
\hline AQI & Remark & Color Code \\
\hline$(0.1)$ & Good & Satisfactory \\
$(0.2)$ & Moderate & \\
\hline$(0.4)$ & Poor & \\
$(0.6)$ & Very Poor \\
\hline$(0.8)$ & Severe \\
\hline
\end{tabular}




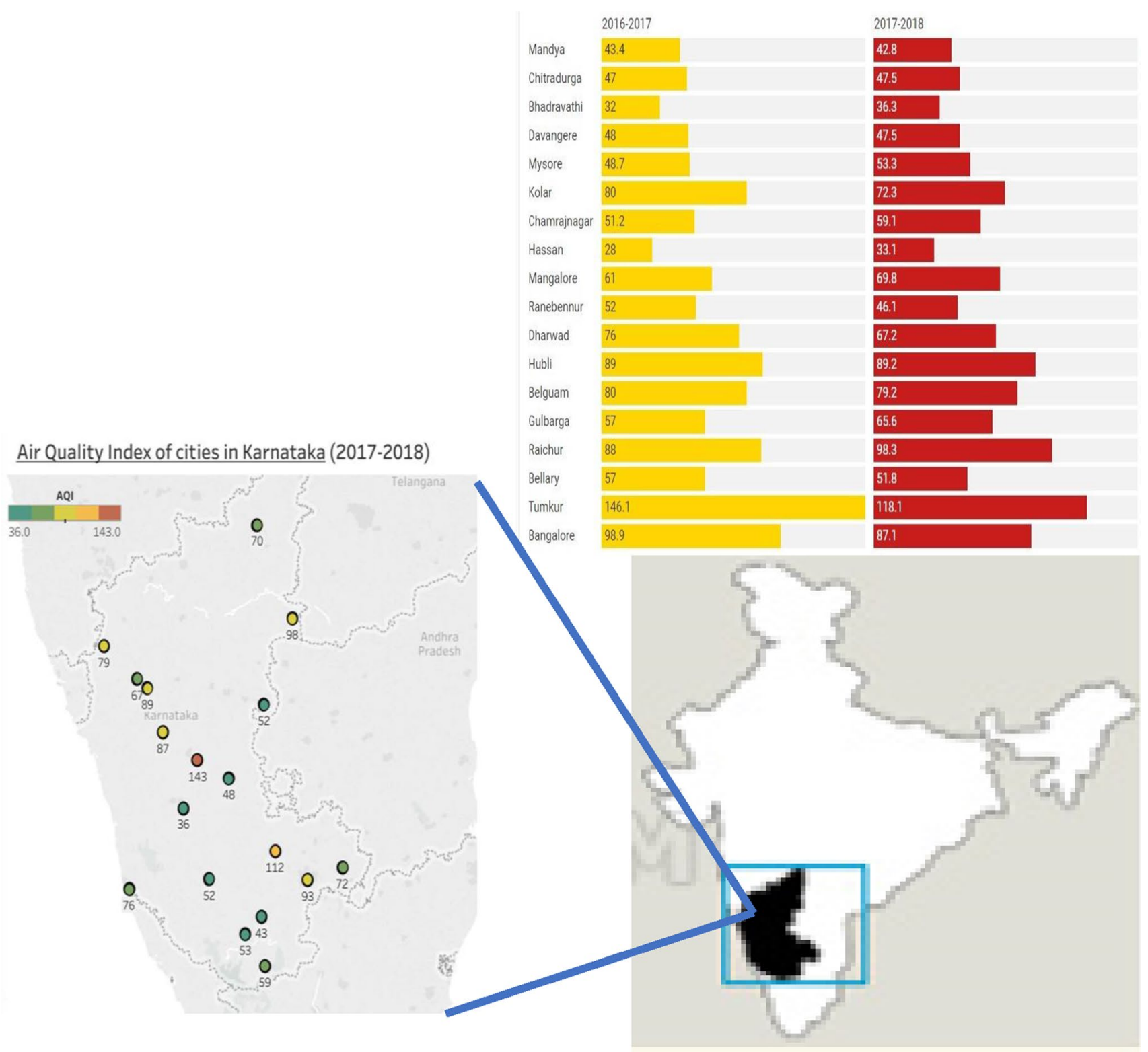

Fig. 1 Reference map of the Air Quality Index of studied cities in Karnataka (2017-2018) and particulate matter across different cities/towns. Source: Karnataka State Pollution Control Board

Central Pollution Control Board [26] listed and ranked different states of India in terms of air pollution. Based on data obtained from the Karnataka State Pollution Control Board (KSPCB) for the three years $(2017,2018,2019)$, this study was assessed air qualities by comparing the concentrations of $\mathrm{PM}_{10}, \mathrm{SO}_{2}$, and $\mathrm{NO}_{2}$ with help of Fuzzy logical statistical tool over the above pre-COVID pandemic period from three main air quality monitoring stations (Bangalore, Mysore and Hubli-Dharwad) within ten different zones of Karnataka (Fig. 1). This study shows that it can be linked to policy framing based on the principle of the polluter paying to control the pollution levels in the environment.

\section{Theoretical design and methodology of this study}

In this study, Air pollution datas of three cities of Karnataka, India was taken such as Bangalore, Mysore, and Hubli-Dharwad. The main contributor is vehicle emission, construction activities and garbage dumping in the city side. The growth of more and more vehicles along with rising population has led to vehicular pollution. Figure 1 shows particulate matter across Bengaluru, Mysore and Hubli-Dharwad in the Karnataka, India. It is shown through temperature scale with three functions represented 
by cold for blue arrow, warm as orange arrow, and hot as red arrow.

Air Quality Indices (AQI) method is related to measuring the concentration of different pollutants $\mathrm{PM}_{10}, \mathrm{NO}_{2}$, $\mathrm{SO}_{2}$ and other pollutants. The fuzzy Logic air quality index calculates in single value of AQI defines limits 0 to 1 . In this study, a comparison of air quality data of three cities was conducted with the help of fuzzy logic algorithm [14]. It used to evaluating Indices through fuzzy multi criteria decision making (MCDM) framework in which linguistic terms of experts opinion and perception, accordingly computing matrix is constructed for sub criteria. There are five linguistic terms used in this framework to create membership functions such as high significant, significant, average significant, low significant and not significant (shown in Table 2). Table 3 shows linguistic terms which driven by field experts.

In fuzzy set theory, triangular and trapezoidal fuzzy sets are used. The graphical representation and expression, of a triangular and trapezoidal membership function, respectively are shown in Fig. 2. The normalized trapezoidal membership function can be expressed as follows:

$\mu(\mathrm{x})=\left\{\begin{array}{c}0 \mathrm{X}<\mathrm{X}_{1} \\ \left(\mathrm{X}-\mathrm{X}_{1}\right) /\left(\mathrm{X}_{2}-\mathrm{X}_{1}\right) \mathrm{X}_{1}<\mathrm{X}<\mathrm{X}_{2} \\ 1 \mathrm{X}_{2}<\mathrm{X}<\mathrm{X}_{3} \\ 4 \\ \left(\mathrm{X}_{4}-\mathrm{X}\right) /\left(\mathrm{X}_{4}-\mathrm{X}_{3}\right) \mathrm{X}_{3}<\mathrm{X}<\mathrm{X}_{4} \\ 0 \mathrm{X}>\mathrm{X}_{4}\end{array}\right.$

The normalized triangular membership function expressed as follows: $\mathrm{X}<\mathrm{X}_{1} \& \mathrm{X}>\mathrm{X}_{3}$

$\mu(\mathrm{x})=\left\{\begin{array}{l}\left(\mathrm{X}-\mathrm{X}_{1}\right) /\left(\mathrm{X}_{2}-\mathrm{X}_{1}\right) \mathrm{X}_{1}<\mathrm{X}<\mathrm{X}_{2} \\ \left(\mathrm{X}_{3}-\mathrm{X}\right) /\left(\mathrm{X}_{3}-\mathrm{X}_{2}\right) \mathrm{X}_{2}<\mathrm{X}<\mathrm{X}_{3}\end{array}\right.$

The principal steps in the application of Fuzzy Multi Criteria Decision Making (MCDM) model, concepts and procedures have given by Zadeh [27], Edwards et al. [28] and Dodgson et al. [29], they identify the following sequence of steps in a typical application. Figure 3 shows presentation of linguistic variables to fuzzy numbers.

Table 2 Graphical representation of fuzzy numbers for linguistic terms

\begin{tabular}{ll}
\hline Linguistic Variables & Fuzzy Numbers \\
\hline $\mathrm{V}_{\mathrm{s}}$ (very significant, very high) & $(0.7,0.8,0.9,1.0)$ \\
$\mathrm{S}$ (significant) & $(0.5,0.6,0.7,0.8)$ \\
$\mathrm{A}_{\mathrm{s}}$ (average significant) & $(0.3,0.4,0.5,0.6)$ \\
$\mathrm{L}_{\mathrm{s}}$ (low significant) & $(0.1,0.2,0.3,0.4)$ \\
$\mathrm{N}_{\mathrm{s}}$ (not significant) & $(0.0,0.0,0.1,0.2)$ \\
\hline
\end{tabular}

Table 3 Linguistic Variables by Experts for Air Quality

\begin{tabular}{llllll}
\hline Sub criteria & Expert 1 & Expert 2 & Expert 3 & Expert 4 & Expert 5 \\
\hline $\mathrm{PM}_{10}$ & $\mathrm{HS}$ & $\mathrm{HS}$ & $\mathrm{S}$ & $\mathrm{S}$ & $\mathrm{HS}$ \\
$\mathrm{SO}_{2}$ & $\mathrm{HS}$ & $\mathrm{HS}$ & $\mathrm{HS}$ & $\mathrm{HS}$ & $\mathrm{HS}$ \\
$\mathrm{NO}_{2}$ & AS & AS & LS & $\mathrm{S}$ & $\mathrm{S}$ \\
\hline
\end{tabular}

The analysis was conducted by consulting five experts who were involved in the air pollution actual field monitoring since long for their opinions about the significance of the air pollution criteria in terms of linguistic variables. Table 3 shows the linguistic variables assigned for air pollution by an actual field experts.

\section{Normalized weightage method}

The below expression is to evaluate the average fuzzy numbers based on linguistic variable as $\mathrm{A}^{\mathrm{k}}{ }_{\mathrm{ij}}$

$$
\begin{array}{r}
\text { Let } A_{i j}^{k}=(1 / p) *\left(a_{i 1}^{k}+a_{i 1}^{k}+\cdots \cdots+a_{i 1}^{k}\right) \\
\text { for } i=1,2, \ldots, n \text { and } j=1,2, ., p
\end{array}
$$

where $\mathrm{p}=$ number of decision-makers involved in the evaluation process.

Using Eq. 1, the linguistic term given by experts can be further simplified to calculate Average fuzzy Number (AFN). The linguistic terms as assigned by experts can be converted to fuzzy numbers used in the above expression through Table 1 and Fig. 2. represent fuzzy membership function into normalized weights for each sub criterion of air quality. Using Eq. (1), the aggregated average for each of the sub criteria is obtained as follows:

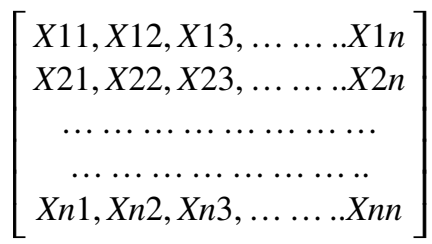

The next step is defuzzification of fuzzy numbers ie. trapezoidal and triangular fuzzy numbers are used to represent the decision maker's opinion and represented by different

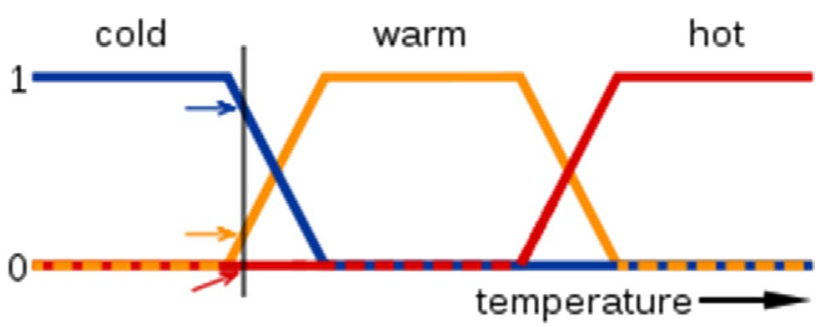

Fig. 2 Mapping a Temperature Scale 
Data Collection for each parameter

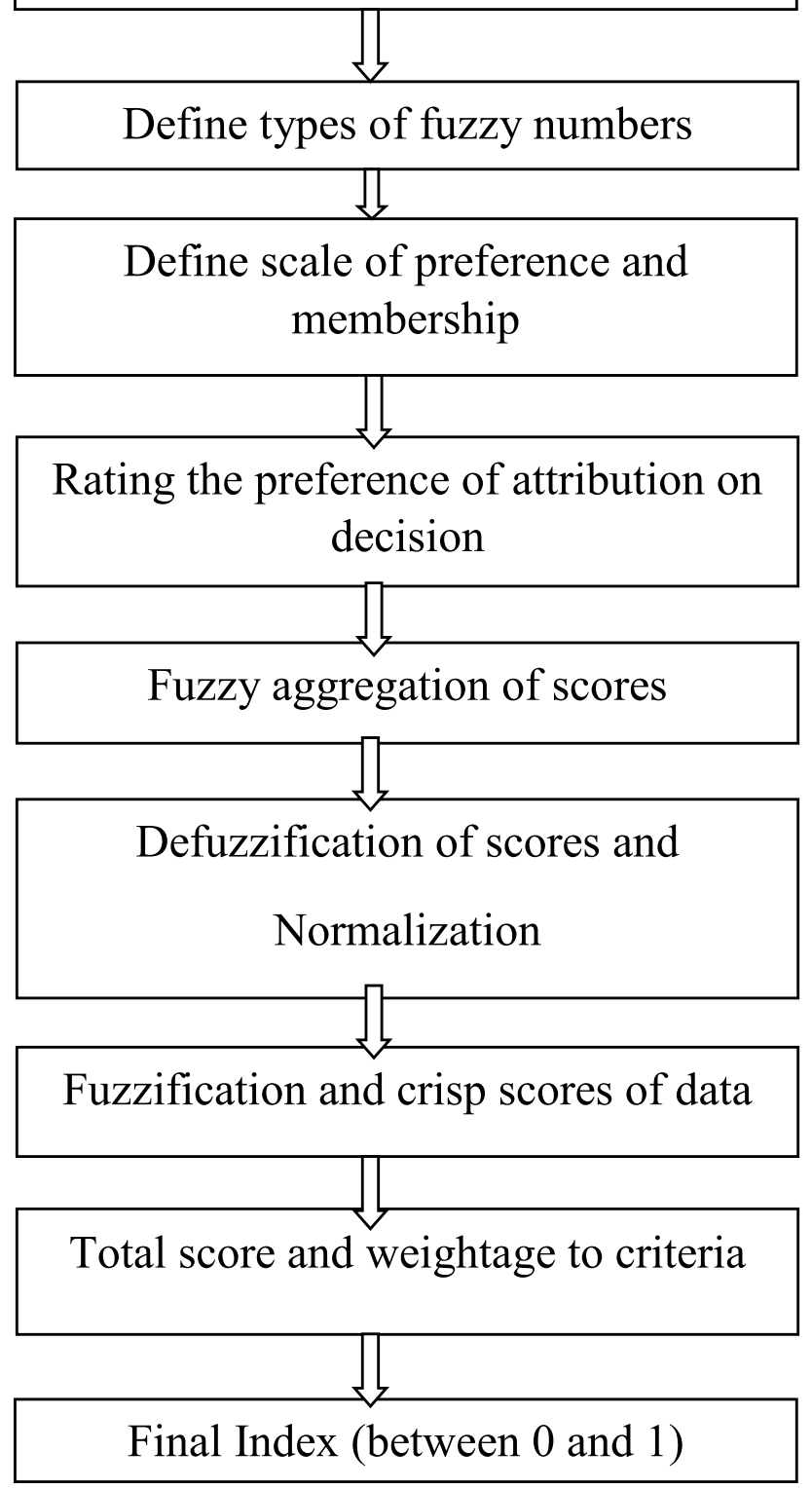

Fig. 3 Fuzzy Decision Framework for Evaluating Indices

operators such as $X_{1}, X_{2}, X_{3}, X_{4}$ as shown in Fig. 2, which denoted by e value (defuzzified) given by Kaufmann and Gupta [30]:

For trapezoidal defuzzy value

$e=\frac{(\mathrm{X} 1+\mathrm{X} 2+\mathrm{X} 3+\mathrm{X} 4)}{4}$

For triangular defuzzy value

$e=\frac{(\mathrm{X} 1+2 \mathrm{X} 2+\mathrm{X} 3)}{4}$
The problem is to find the various indices related to the environment. The observations are converted into membership functions. The normalized membership function will be in the form of $[0,1]$.

\section{Normalizing the criterion}

After normalized of membership function, all the air pollution parameters converted into fuzzy numbers based on the specified statutory norms. For example, if PM of a given sample is $60 \mu \mathrm{g} / \mathrm{m}^{3}$, the membership function of that sample then would be 0.6 see in Fig. 4, as the permissible limit of PM is $100 \mu \mathrm{g} /$ $\mathrm{m}^{3}$. The MCDM model derived from integral part of these fuzzy sets and given below as a matrix for all sub criteria for raw air quality datas:

$X k=\left[\begin{array}{c}a 1 \\ b 1 \\ c 1 \\ d 1 \\ e 1 \\ f 1 \\ g 1 \\ h 1\end{array}\right]$

where $\mathrm{a}_{1}, \mathrm{~b}_{1,} \mathrm{c}_{1,} \mathrm{~d}_{1,} \mathrm{e}_{1,} \mathrm{f}_{1}, \mathrm{~g}_{1}, \mathrm{~h}_{1}$ are fuzzy values of different parameters.

Total score for sub criteria.

Hwang and Yoon [31] given expression for calculating total score (TS) for each parameter as follow.

$\mathrm{TS}=\sum\left(\mathrm{N}_{\mathrm{i}} * \mathrm{~W}(\mathrm{Ci})\right)$ for $\mathrm{I}=1,2,3 \ldots . \mathrm{n}$

where $\mathrm{W}\left(\mathrm{C}_{\mathrm{i}}\right)=$ weight of the sub criterion $\mathrm{k}$, and $\mathrm{N}_{\mathrm{i}}=$ normalized value of the indicator against the sub criterion $\mathrm{k}$. The normalized weight for each sub criterion can be obtained by dividing the defuzzified value of each sub criterion $(\mathrm{Cij})$ by the sum total of defuzzified value of all sub criteria $\left(\sum \mathrm{Cij}\right)$.

\section{Results and discussion}

On the basis of data which was collected from the Karnataka Pollution Control Board, India an air quality index was developed for 2017, 2018 and 2019 years. Table 4 shows the yearly average status of air pollution at different monitoring stations such as Bangalore, Mysore, and Hubli-Dharwad. Based on the linguistic variables shown in Table 3, fuzzy numbers calculated based on linguistic variables and defuzzification of fuzzy numbers by means of trapezoidal numbers used to represent the decision makers. The normalized weightage for each sub criteria is obtained by dividing the 


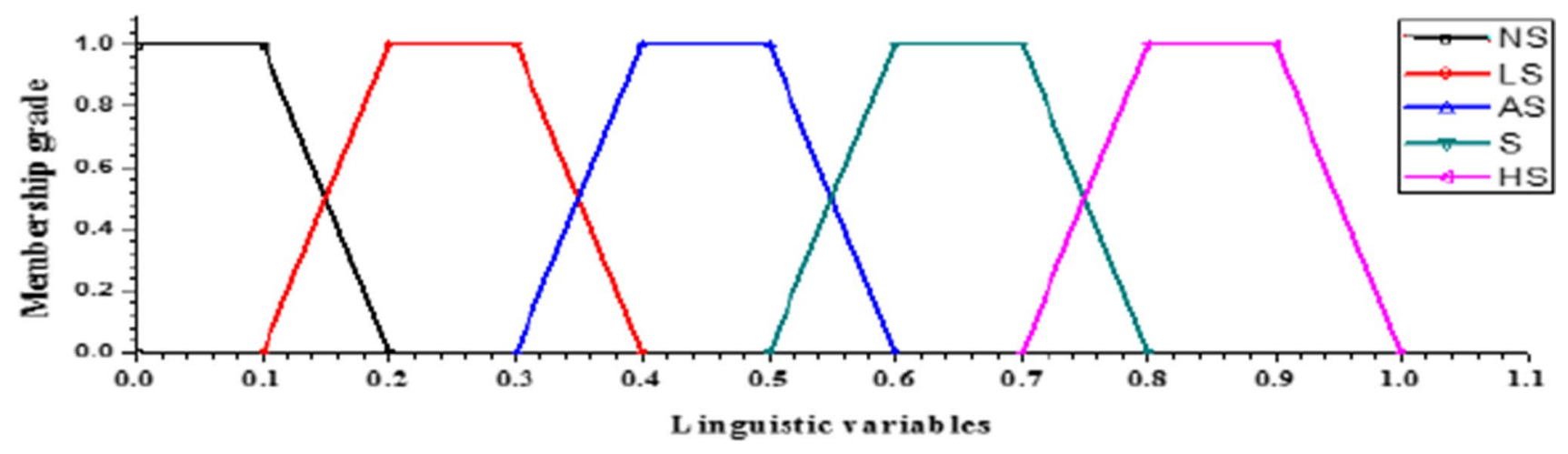

Fig. 4 Graphical Representation of Trapezoidal Membership Function in Linguistic terms

defuzzified scores of each sub criteria by the total of all the sub criteria [32-36].

Table 5 gives the values of normalized weight for each sub criteria. All the yearly average values are converted to membership functions based on the specified statutory norms as shown in Table 5. Table 6 shows normalized Data for each Sub Criterion of Air Quality. The normalized value for each station ie. White field road, Rail wheel factory, Victorial Hospital, Yeswanthapura, TERI office, Banasawadi (S1-S6) in Bangalore city and for the year 2017, 2018, 2019 represented in the matrix form as shown below:

\begin{tabular}{|c|c|c|c|c|c|c|c|}
\hline SI & 2 & S3 & S4 & S5 & S6 & $w t$ & \\
\hline 0.37 & 0.37 & 0.37 & 0.37 & 0.37 & 0.37 & 0.37 & \\
\hline 0.016 & 0.016 & 0.016 & 0.016 & 0.016 & 0.016 & 0.40 & \\
\hline 19 & 0.16 & 0. & 0.2 & 0. & 0.1 & 3 & \\
\hline $\mathrm{S}$ & 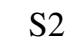 & $\mathrm{S}$ & S & S & S & $W i$ & \\
\hline 0.37 & 0.37 & 0.37 & 0.37 & 0.37 & 0.3 & .37 & \\
\hline 0.016 & 0. & 0.01 & 0.0 & 0.0 & 0. & 0.40 & \\
\hline 0.182 & 0.171 & 0.182 & 0.190 & 0.186 & 0.140 & 0.23 & \\
\hline S1 & $\mathrm{C}$ & S & $\mathrm{S} 4$ & S5 & S & $W i$ & \\
\hline 0.37 & 0.3 & 0.37 & 0.37 & 0.37 & 0.3 & 0.37 & \\
\hline 0. & & & 0.8 & 0.0 & & 0.4 & \\
\hline 1. & & & 1 & & 01 & 0.2 & \\
\hline
\end{tabular}

Based on fuzzy logic normalized analyse, overall Score of AQI for each station were found to be $0.541,0.536$, $0.536,0.523,0.547,0.507$, respectively.

Table 7 shows the yearly average status of air pollution at different monitoring stations for the year 2017, 2018 and

Table 4 Yearly Average Status of Ambient Air Quality* Monitoring Station

\begin{tabular}{|c|c|c|c|c|c|c|c|}
\hline \multirow[t]{2}{*}{ Sub criteria } & \multirow[t]{2}{*}{ NAAQs } & \multicolumn{6}{|l|}{ Monitoring station } \\
\hline & & White field road & $\begin{array}{l}\text { Rail wheel factory, } \\
\text { Yelahanka }\end{array}$ & $\begin{array}{l}\text { Victorial } \\
\text { Hospital }\end{array}$ & Yeswanthapura & $\begin{array}{l}\text { TERI office, } \\
\text { Domlur }\end{array}$ & Banasawadi \\
\hline \multicolumn{8}{|l|}{2017} \\
\hline $\mathrm{PM}_{10}$ & 60 & 130.9 & 110.8 & 79.9 & 93.3 & 120.1 & 80.3 \\
\hline $\mathrm{SO}_{2}$ & 50 & 2.0 & 2.0 & 2.0 & 2.0 & 2.0 & 2.0 \\
\hline $\begin{array}{l}\mathrm{NO}_{2} \\
2018\end{array}$ & 40 & 33.1 & 28.5 & 36.3 & 39.6 & 32.0 & 26.8 \\
\hline $\mathrm{PM}_{10}$ & 60 & 103.9 & 101.9 & 65.3 & 95 & 118.4 & 68.7 \\
\hline $\mathrm{SO}_{2}$ & 50 & 2.0 & 2.0 & 2.0 & 2.0 & 2.0 & 2.0 \\
\hline $\begin{array}{l}\mathrm{NO}_{2} \\
2019\end{array}$ & 40 & 31.7 & 29.7 & 31.7 & 33 & 32.4 & 24.3 \\
\hline $\mathrm{PM}_{10}$ & 60 & 92 & 92 & 55 & 74 & 86 & 74 \\
\hline $\mathrm{SO}_{2}$ & 50 & 2.0 & 2.0 & 2.0 & 2.0 & 2.0 & 2.0 \\
\hline $\mathrm{NO}_{2}$ & 40 & 27 & 26 & 26 & 29 & 28 & 21 \\
\hline
\end{tabular}

*All the parameters are expressed in $\mu \mathrm{g} / \mathrm{m}^{3}$ 
Table 5 Normalized Weights for each Sub Criterion of Air Quality

\begin{tabular}{lllllll}
\hline Sub criteria & \multicolumn{3}{l}{ Average fuzzy no for each sub criteria } & & $\begin{array}{l}\text { De-fuzzified } \\
\text { value }\end{array}$ & Normalized weight \\
\cline { 2 - 5 } & $\mathrm{X}_{1}$ & $\mathrm{X}_{2}$ & $\mathrm{X}_{3}$ & $\mathrm{X}_{4}$ & & $\mathrm{e}$ \\
\hline $\mathrm{PM}_{10}$ & 0.62 & 0.72 & 0.82 & 0.92 & 0.77 & $\mathrm{w}$ \\
$\mathrm{SO}_{2}$ & 0.7 & 0.8 & 0.9 & 1 & 0.85 & 0.36492891 \\
$\mathrm{NO}_{2}$ & 0.34 & 0.44 & 0.54 & 0.64 & 0.49 & 0.402843602 \\
& & & & $\mathrm{SUM}$ & 2.11 & 1 \\
\hline
\end{tabular}

Table 6 Normalized Data for each Sub Criterion of Air Quality

\begin{tabular}{|c|c|c|c|c|c|c|c|}
\hline \multirow[t]{2}{*}{ Sub criteria } & \multirow[t]{2}{*}{ NAAQs } & \multicolumn{6}{|c|}{ Monitoring station } \\
\hline & & White field road & $\begin{array}{l}\text { Rail wheel fac- } \\
\text { tory, Yelahanka }\end{array}$ & Victorial Hospital & Yeswanthapura & $\begin{array}{l}\text { TERI office, } \\
\text { Domlur }\end{array}$ & Banasawadi \\
\hline \multicolumn{8}{|l|}{2017} \\
\hline $\mathrm{PM}_{10}$ & 60 & 1 & 1 & 1 & 1 & 1 & 1 \\
\hline $\mathrm{SO}_{2}$ & 50 & 0.04 & 0.04 & 0.04 & 0.04 & 0.04 & 0.04 \\
\hline $\begin{array}{l}\mathrm{NO}_{2} \\
2018\end{array}$ & 40 & 0.8275 & 0.7125 & 0.9075 & 0.99 & 0.80 & 0.67 \\
\hline $\mathrm{PM}_{10}$ & 60 & 1 & 1 & 1 & 1 & 1 & 1 \\
\hline $\mathrm{SO}_{2}$ & 50 & 0.04 & 0.04 & 0.04 & 0.04 & 0.04 & 0.04 \\
\hline $\begin{array}{l}\mathrm{NO}_{2} \\
2019\end{array}$ & 40 & 0.793 & 0.743 & 0.793 & 0.825 & 0.810 & 0.608 \\
\hline $\mathrm{PM}_{10}$ & 60 & 1 & 1 & 0.917 & 1 & 1 & 1 \\
\hline $\mathrm{SO}_{2}$ & 50 & 0.040 & 0.040 & 0.040 & 0.040 & 0.040 & 0.040 \\
\hline $\mathrm{NO}_{2}$ & 40 & 0.675 & 0.650 & 0.650 & 0.725 & 0.700 & 0.525 \\
\hline
\end{tabular}

2019 in Mysore. Table 8 shows normalized Data for each Sub Criterion of Air Quality. The normalized value for each station ie. KSRTC, K.R circle, KSPCB office (S1-S2) in Mysore city and for the year 2017, 2018, 2019 represented in the matrix form as shown below:

\begin{tabular}{|c|c|c|c|}
\hline S1 & S2 & $W i$ & PM10 \\
\hline 0.300 & 0.290 & 0.37 & \\
\hline 0.018 & 0.017 & 0.40 & \\
\hline 0.108 & 0.114 & 0.23 & \\
\hline S1 & $\mathrm{S} 2$ & $W i$ & PM10 \\
\hline 0.329 & 0.286 & 0.37 & SO? \\
\hline 0.018 & 0.018 & 0.40 & NO? \\
\hline 0.097 & 0.095 & 0.23 & 1002 \\
\hline $\mathrm{S} 1$ & S2 & $W i$ & PM10 \\
\hline 0.327 & 0.276 & 0.37 & SO2 \\
\hline 0.016 & 0.017 & 0.40 & NO2 \\
\hline 0.086 & 0.091 & 0.23 & \\
\hline
\end{tabular}

Based on fuzzy logic normalized analyze, overall Score of AQI for each station were found to be 0.426 and 0.421 , respectively.

Table 9 shows the yearly average status of air pollution at different monitoring stations for the year 2017, 2018 and
2019 in Hubli-Dharwad. Table 10 shows normalized Data for each Sub Criterion of Air Quality. The normalized value

Table 7 Yearly Average Status of Ambient Air Quality* Monitoring Station

\begin{tabular}{lllr}
\hline Sub criteria & NAAQs & \multicolumn{2}{l}{ Monitoring station } \\
\cline { 3 - 4 } & & $\begin{array}{l}\text { KSRTC, K.R } \\
\text { circle }\end{array}$ & KSPCB office \\
& & & \\
\hline 2017 & 60 & 48.7 & 47.0 \\
$\mathrm{PM} 10$ & 50 & 2.2 & 2.1 \\
$\mathrm{SO}_{2}$ & 40 & 18.8 & 19.8 \\
$\mathrm{NO}_{2}$ & & & \\
2018 & 60 & 53.3 & 46.4 \\
$\mathrm{PM}_{10}$ & 50 & 2.2 & 2.3 \\
$\mathrm{SO}_{2}$ & 40 & 16.8 & 16.6 \\
$\mathrm{NO}_{2}$ & & & \\
2019 & 60 & 53 & 44.1 \\
$\mathrm{PM}_{10}$ & 50 & 2.0 & 2.5 \\
$\mathrm{SO}_{2}$ & 40 & 15 & 18.6 \\
$\mathrm{NO}_{2}$ & & &
\end{tabular}

${ }^{*}$ All the parameters are expressed in $\boldsymbol{\mu g} / \mathbf{m}^{3}$ 
Table 8 Normalized Data for each Sub Criterion of Air Quality

\begin{tabular}{llll}
\hline Sub criteria & NAAQs & \multicolumn{2}{l}{ Monitoring station } \\
\cline { 3 - 4 } & & $\begin{array}{l}\text { KSRTC, K.R } \\
\text { circle }\end{array}$ & KSPCB office \\
& & & \\
\hline 2017 & 60 & 0.812 & 0.783 \\
$\mathrm{PM}_{10}$ & 50 & 0.044 & 0.042 \\
$\mathrm{SO}_{2}$ & 40 & 0.470 & 0.495 \\
$\mathrm{NO}_{2}$ & & & \\
2018 & 60 & 0.888 & 0.773 \\
$\mathrm{PM}_{10}$ & 50 & 0.044 & 0.046 \\
$\mathrm{SO}_{2}$ & 40 & 0.420 & 0.415 \\
$\mathrm{NO}_{2}$ & & & \\
2019 & 60 & 0.883 & 0.781 \\
$\mathrm{PM}_{10}$ & 50 & 0.040 & 0.044 \\
$\mathrm{SO}_{2}$ & 40 & 0.375 & 0.335 \\
$\mathrm{NO}_{2}$ & &
\end{tabular}

for each station ie. KSPCB office, Dharwad, Gokul road, Hubli (S1-S2) in Hubli-Dharwad city and for the year 2017, 2018, 2019 represented in the matrix form as shown below:

\begin{tabular}{|c|c|c|c|}
\hline S1 & $\mathrm{S} 2$ & $W i$ & PM10 \\
\hline 0.370 & 0.371 & 0.37 & \\
\hline 0.044 & 0.045 & 0.40 & \\
\hline 0.127 & 0.127 & 0.23 & INU \\
\hline S1 & $\mathrm{S} 2$ & $W i$ & PM1 \\
\hline 0.370 & 0.371 & 0.37 & $\mathrm{SO}$ \\
\hline 0.042 & 0.045 & 0.40 & \\
\hline 0.123 & 0.152 & 0.23 & 1002 \\
\hline $\mathrm{S} 1$ & $\mathrm{~S} 2$ & $W i$ & SM10 \\
\hline 0.370 & 0.370 & 0.37 & $\mathrm{SO}$ \\
\hline 0.032 & 0.040 & 0.40 & \\
\hline 0.098 & 0.121 & 0.23 & \\
\hline
\end{tabular}

Based on fuzzy logic normalized analyze, overall Score of AQI for each station were found to be 0.541 and 0.542 , respectively. The total matrix is obtained by the following equation:

$\mathrm{TS}=\sum \mathrm{N}_{\mathrm{i}} \cdot \mathrm{W}_{\mathrm{i}}$ for $\mathrm{i}=1,2,3 \ldots \mathrm{n}$.

where $\mathrm{W}(\mathrm{i})=$ weight of sub criterion $\mathrm{k}$, and $\mathrm{N}_{\mathrm{i}}=$ normalized value of the monitoring station against the sub criterion $i$.

Using simple additive weighting method, the overall score for each city was developed and is shown in Table 11. Table 11 shows that AQI score for six monitoring station of Bangalore city for the year 2017 in which we found that, the Banasawadi monitoring station have least air quality score which is 0.540 while Yeswanthapura monitoring station has maximum air quality score which is about 0.614 . From, it is clear that the AQI for the year 2018 of some monitoring stations of Bangalore was decreased as compared to the AQI
Table 9 Yearly Average Status of Ambient Air Quality Monitoring Station

\begin{tabular}{llll}
\hline Sub criteria & NAAQs & \multicolumn{2}{l}{ Monitoring station } \\
\cline { 3 - 4 } & & $\begin{array}{l}\text { KSPCB office, } \\
\text { Dharwad }\end{array}$ & $\begin{array}{l}\text { Gokul } \\
\text { Road, } \\
\text { Hubli }\end{array}$ \\
\hline 2017 & & \\
$\mathrm{PM}_{10}$ & 60 & 76.0 & 89.0 \\
$\mathrm{SO}_{2}$ & 50 & 5.5 & 5.6 \\
$\mathrm{NO}_{2}$ & 40 & 22.1 & 22.0 \\
2018 & & & \\
$\mathrm{PM}_{10}$ & 60 & 67.2 & 89.2 \\
$\mathrm{SO}_{2}$ & 50 & 5.2 & 5.6 \\
$\mathrm{NO}_{2}$ & 40 & 21.4 & 26.4 \\
2019 & & & 76 \\
$\mathrm{PM}_{10}$ & 60 & 62 & 5 \\
$\mathrm{SO}_{2}$ & 50 & 4 & 21 \\
$\mathrm{NO}_{2}$ & 40 & 17 & \\
\hline
\end{tabular}

*All the parameters are expressed in $\mu \mathrm{g} / \mathrm{m}^{3}$

for the year 2017. AQI of Banasawadi monitoring station is least while Yeswanthapura monitoring station is maximum. AQI for Banasawadi is 0.526 and for Yeswanthapura is 0.576. In 2019-year, TERI office, Domlur is found out the highest AQI and Banasawadi is the lowest AQI. AQI value at TERI office, Domlur monitoring station is 0.547 and at Banasawadi is 0.507 .

Table 11 shows that AQI score for two monitoring station of Mysore city for the year 2017 in which we found that, the KSPCB office monitoring station have least air quality score which is 0.421 while KSRTC, K.R circle monitoring station

Table 10 Normalized Data for each Sub Criterion of Air Quality

\begin{tabular}{llll}
\hline Sub criteria & NAAQs & \multicolumn{2}{l}{ Monitoring station } \\
\cline { 3 - 4 } & & $\begin{array}{l}\text { KSPCB office, } \\
\text { Dharwad }\end{array}$ & $\begin{array}{l}\text { Gokul } \\
\text { road, } \\
\text { Hubli }\end{array}$ \\
\hline 2017 & & & \\
$\mathrm{PM}_{10}$ & 60 & 1 & 1 \\
$\mathrm{SO}_{2}$ & 50 & 0.110 & 0.112 \\
$\mathrm{NO}_{2}$ & 40 & 0.553 & 0.550 \\
2018 & & & \\
$\mathrm{PM}_{10}$ & 60 & 1 & 1 \\
$\mathrm{SO}_{2}$ & 50 & 0.104 & 0.112 \\
$\mathrm{NO}_{2}$ & 40 & 0.535 & 0.660 \\
2019 & & & 1 \\
$\mathrm{PM}_{10}$ & 60 & 1 & 0.100 \\
$\mathrm{SO}_{2}$ & 50 & 0.080 & 0.525 \\
$\mathrm{NO}_{2}$ & 40 & 0.425 &
\end{tabular}


Table 11 Overall Score of Air Pollution in different cities

\begin{tabular}{llll}
\hline & \multicolumn{3}{l}{ Air Quality Index } \\
\cline { 2 - 4 } Monitoring station & \multicolumn{3}{l}{ Overall score } \\
\cline { 2 - 4 } & 2017 & 2018 & 2019 \\
\hline White field road & 0.576 & 0.568 & 0.541 \\
Rail wheel factory, Yelahanka & 0.550 & 0.557 & 0.536 \\
Victorial Hospital & 0.595 & 0.568 & 0.536 \\
Yeswanthapura & 0.614 & 0.576 & 0.523 \\
TERI office, Domlur & 0.570 & 0.572 & 0.547 \\
Banasawadi & 0.540 & 0.526 & 0.507 \\
KSRTC, K.R circle & 0.426 & 0.444 & 0.429 \\
KSPCB office & 0.421 & 0.399 & 0.387 \\
KSPCB office, Dharwad & 0.541 & 0.535 & 0.500 \\
Gokul road, Hubli & 0.542 & 0.567 & 0.531 \\
\hline
\end{tabular}

have maximum air quality score which is about 0.426 . Table 11, shows that AQI at KSPCB office monitoring station is least 0.399 and highest air quality index monitoring station is KSRTC, K.R circle is 0.444 . it is decreasing as compared to the year 2017. Table 11 shows that AQI score for two monitoring station of Hubli-Dharwad city for the year 2017 in which we found that, the KSPCB office, Dharwad monitoring station have least air quality score which is 0.541 while Gokul road, Hubli monitoring station have maximum air quality score which is about 0.542 .

Table 11 shows that air quality index score for two monitoring station of Hubli-Dharwad city for the year 2018 in which we found that, the KSPCB office, Dharwad monitoring station have least air quality score which is 0.535 while Gokul road, Hubli monitoring station have maximum air quality score which is about 0.567 . Some of researchers recently shows improvement of air quality during COVID-19 in the different states of India [10, 12]. They analysed in Delhi and Gujarat (mainly Industrial monitoring stations) states of India and found $40-50 \%$ and $30-84 \%$ reduction in PM2.5, PM10, $\mathrm{NO}_{2}, \mathrm{SO}_{2}, \mathrm{CO}$ and $\mathrm{NH}_{3}$ concentrations through provided data from National Air Quality Index (NAQI), respectively [37]. Using a simple additive weighting method, the overall score for each city was developed and is shown in Fig. 4.

Figure 5 shows the AQI for three cities in Karnataka in the year 2017, 2018 and 2019 in which we found that Mysore has the least air quality score and Bangalore have the maximum air quality score that is 0.424 and 0.574 . Figure 5 shows the AQI for three cities in Karnataka in the year 2018 in which we found that Mysore has the least air quality score and Bangalore have the maximum air quality score that is 0.422 and 0.561 . Chinnaswamy et al. [4] reported that trends on level of particulate matter through statistical analysis and found day-by-day air pollutant increased in the eight region of Bangalore, India.

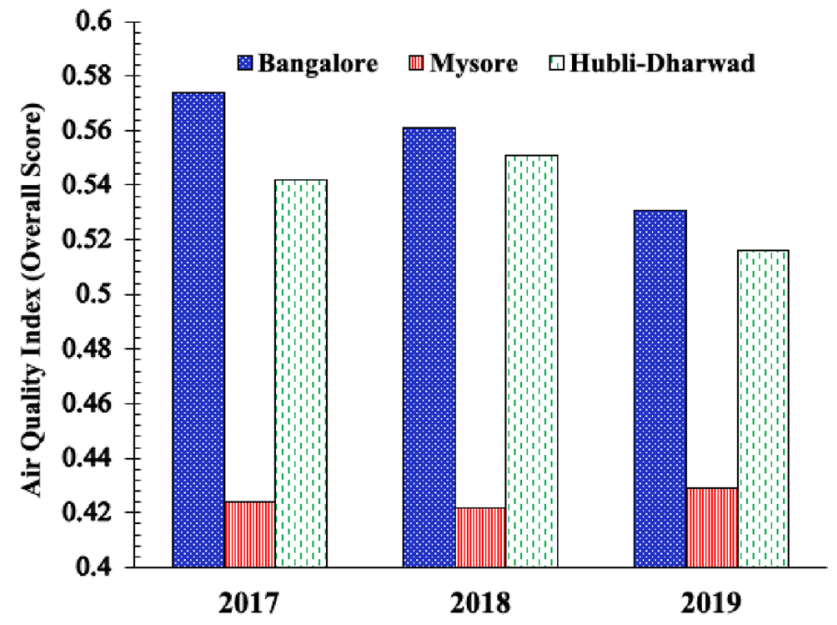

Fig. 5 Overall Score of Air Pollution at different cities

Figure 5 shows the AQI for three cities in Karnataka in the year 2019 in which we found that Mysore has the least air quality score and Bangalore have the maximum air quality score that is 0.429 and 0.531 . Pereira et al. [13] studied on impact of ventilation and filtration conditions on particle concentrations in an orthopaedic operating room. Due to their study after new air filter, total and viable particle concentrations were found to be $0.3 \times 10^{6} \pm 0.1 \times 10^{6}$ particles/ $\mathrm{m}^{3}$ and $15 \mathrm{CFU} / \mathrm{m}^{3}$, respectively. Initial concentrations of total and viable particle were $0.4 \times 10^{6} \pm 0.2 \times 10^{6}$ particles/ $\mathrm{m}^{3}$ and $24 \mathrm{CFU} / \mathrm{m}^{3}$, respectively. They found regular maintenances of air filter inside the ventilator which helps good quality of air in the room.

\section{Conclusion}

This study is to assess air qualities by comparing the concentrations of $\mathrm{PM}_{10}, \mathrm{SO}_{2}$, and $\mathrm{NO}_{2}$ with help of Fuzzy logical statistical tool over pre-COVID pandemic years (2017 to 2019) from three air quality monitoring stations (Bangalore, Mysore and Hubli-Dharwad cities of Karnataka, India) within ten different zones of Karnataka. The following results are obtained as follow:

- In Bangalore, pollution level decrease as compared by yearly bases in the year 2017 was 0.574 and in the year 2019 was 0.531 that decreases the value of air quality index by $-0.074912 \%$. - ve sign shows a decrease in level.

- In Hubli-Dharwad pollution level increase in the year, 2018 compared to the year 2017 by $0.016605 \%$ and in the year 2019 decrease pollution level by $-0.0635208 \%$.

- Mysore is the least pollution level city as compared to Bangalore and Hubli-Dharwad. Pollution level increased by $0.011792 \%$. 
- Overall based on AQI for all the three pre-COVID pandemic years, Mysore city shows the least value, Hubli-Dharwad shows moderate value, and Bangalore shows the maximum value i.e., Bangalore $>$ Hubli-Dharwad $>$ Mysore.

This study shows that it can be linked to policy framing based on the principle of the polluter paying to control the pollution levels in the environment. This study also reveals air pollution level in term of AQI for pre-COVID pandemic years are little higher than present post-COVID pandemic situation.

Acknowledgements The authors wish to thanks Karnataka Pollution Control Board, Bangalore (India) for sharing data of Air Quality Index of various cities.

Authors' contributions S. Suresh- Develop the write up and final submission.

Rahul Modi- data collecting and analysis

A.K. Sharma- Final drafting of manuscript

S. Arisutha- Analysis the simulation results

Mika Sillanpaa- Final editing of manuscript

Data availability Open to reader.

\section{Declarations}

Competing interests I declare that no any conflict of interest with all co-authors.

\section{References}

1. Yadav J, Kharat V, Deshpande A. Fuzzy description of air quality using fuzzy inference system with degree of match via computing with words: A case study. Air Quality Atmosphere Health. 2014;7(3):325-34.

2. World Health Organization (WHO) 2015 Promoting Healthy Life. The World Health Report. - Reducing Risks. World Health Organization (WHO). Bonn, Germany: Health Aspects of Air Pollution with Particulate Matter Ozone and Nitrogen Dioxide, WHO; 2002.

3. Balakrishnan K, Cohen A, Smith K. Addressing the burden of disease attributable to air pollution in India: the need to integrate across household and ambient air pollution exposures. Environ Health Prospect. 2014;122(1):A6-7.

4. Chinnaswamy AK, Galvez MCD, Balisane H, Nguyen QT, Nagui RNG, Trodd N, Marshall IM, Yaaco N, Santos GNC, Vallar EA, Shaker M, Wickramasinghe N, Ton TN. Air pollution in Bangalore, India: an eight-year trend analysis. Int J Environ Technol Manage. 2016; 19 (3/4).

5. Mehmood K, Saifullah Iqbal M, Abrar MM. Can exposure to PM2.5 particles increase the incidence of coronavirus disease, (COVID-19)? Sci Total Environ. 2019;2020(741):140441.

6. World Health Organization (WHO). Clinical Management of Severe Acute Respiratory Infection when novel coronavirus (2019-nCoV) Infection is Suspected: Interim Guidance, Clinical management of Severe Acute Respiratory Infection when Novel Coronavirus (2019-nCoV) Infection is suspected: Interim Guidance. 2020, P.21-22.
7. Ricco M, Ranzieri S, Balzarini F, Bragazzi NL, Corradi M. SARSCoV-2 infection and air pollutants: Correlation or causation? Sci Total Environ. 2020;734:139489.

8. Kerimray A, Baimatova N, Ibragimova OP, Bukenov B, Kenessov B, Plotitsyn P, Karaca F. Assessing air quality changes in large cities during COVID-19 lockdowns: The impacts of traffic-free urban conditions in Almaty. Kazakhstan Science of the Total Environment. 2020;730:139179.

9. Dantas G, Siciliano B, França BB, Silva CMD, Arbilla G. The impact of COVID-19 partial lockdown on the air quality of the city of Rio de Janeiro. Brazil Sci Total Environ. 2020;729:139085.

10. Mahato S, Krishna SP, Ghosh G. Effect of lockdown amid COVID-19 pandemic on air quality of the megacity Delhi. India Sci Total Environ. 2020;730:139086.

11. Zangari S, Hill DT, Charette AT, Mirowsky JE. Air quality changes in New York City during the COVID-19 pandemic. Sci Total Environ. 2020;742:140496.

12. Selvam S, Muthukumar P, Venkatramanan S, Roy PD, Bharath KM, Jesuraja K. SARS-CoV-2 pandemic lockdown: Effects on air quality in the industrialized Gujarat state of India. Sci Total Environ. 2020;737:140391.

13. Pereira ML, Vilain R, Kawase PR, Tribess A, Morawska L. Impact of Filtration Conditions on Air Quality in an Operating Room. Int J Environ Res. 2020. https://doi.org/10.1007/s41742-020-00286-X.

14. Balmat JF, Lafont F, Maifret R, Pessel N. Maritime Risk Assessment (MARISA), a fuzzy approach to define an individual ship risk factor. Ocean Eng. 2009;36:1278-86.

15. EPI (Environmental Performance Index). Global Metrics for the Environment-The Environmental Performance Index Ranks Countries Performance on High-priority Environmental Issues. 2016. p. 23.

16. Guerreiro CBB, Foltescu V, Leeuw FD. Air quality status and trends in Europe. Atmospheric Environ. 2014;98:376-84.

17. Yu L, He H, Zhang G. Application of Fuzzy synthetic evaluation of air quality assessment in the selected cities of china. International Journal of Environmental Protection and Policy. 2018;6(2):50-5.

18. Karnataka State Pollution Control Board (KSPCB), Ambient Air Quality Monitoring [online] http://kspcb.gov.in/ambient_air_quali ty.htm, accessed 30 June 2019.

19. Yang Z, Wang J. A new air quality monitoring and early warning system: Air quality assessment an air pollutant concentration prediction. Environ Res. 2017;158:105-17.

20. Chauhan VS, Singh B, Ganesh S, Chauhan DS, Gupta S, Gunjan S, Zaidi J. Air Pollution in Jhansi: Air quality indexing and statistical analysis. Octa J Environ Res. 2016;4:51-7.

21. Singh D, Tiong LKR. A Fuzzy Decision Framework for Contractor Selection. J Const Eng Manage ASCE. 2005;131:62-70.

22. Moraga $\mathrm{C}$, Temme KH. Functional equivalence between s-neural networks and fuzzy models. Technol Construct Intell Syst. 2002;2:355-363.

23. Debnath J, Majumder D, Biswas A. Integrated model based on interval type 2 Fuzzy reasoning approach and Fuzzy analytic assessment of air quality in urban area. 2018;46:133-146.

24. Lad RK, Christian RA, Deshpande AW. A Fuzzy MCDM Framework For The Environmental Pollution Potential Of Industries Focusing On Air Pollution. 2008;116:617-26.

25. Christian RA, Lad RK, Deshpande AW, Desai NG. Fuzzy MCDM approach for addressing composite index of water and air pollution potential of industries. Inter J Digital Content Technol Appl. 2008;2(2):64-71.

26. Central Pollution Control Board (CPCB). Air Quality Assessment, Emission Inventory and Source Apportionment Study for Indian Cities. 2015.

27. Zadeh LA. Fuzzy sets. Inform Cont. 1965;8(3):338-53. 
28. Dodgson JS, Spackman M, Pearman AD, Philips LD. Multi-criteria analysis: a manual. 2009. p. 2-3.

29. Edwards W, Barron FH. SMARTS and SMARTER: improved simple methods for multi-attribute utility measurement. Organizational Behaviour and Human Decision Processes. 1994;60:305-25.

30. Kaufmann A, Gupta MM. Introduction to Fuzzy Arithmetic. New York: Van Nostrand Reinhold Co.; 1985.

31. Hwang CL, Yoon K. Multiple Attribute Decision Making: Methods and Applications. New York: Springer; 1981.

32. Mishra D, Goyal P. Neuro - Fuzzy approach to forecast $\mathrm{NO}_{2}$ pollutants assessed to air quality dispersion model over, Delhi. India Aerosol Air Qual Res. 2016;16:166-74.

33. Olvera-García M, Carbajal-Hernández J, Sánchez-Fernández LP, Hernandex-Bautista I. Air quality assessment using a weighted Fuzzy Inference System. Ecolog Infor. 2016;33:57-74.
34. Upadhyaya G, Dashore N. Fuzzy logic-based model for monitoring air quality index. Indian J Sci Technol. 2011;4(3):15-218.

35. Wang B, Chen Z. A model-based Fuzzy set-OWA approach for integrated air pollution risk assessment. Stoch Environ Res Risk Assess. 2015;29(5):1413-26.

36. Yuan X, Mu R, Zuo J, Wang Q. Economic Development, Energy Consumption, and Air Pollution: A Critical Assessment in China. Human Ecolog Risk Assess: An Intern J. 2015;21(3):781-98.

37. National ambient air quality (NAAQ) standard New Delhi, 2014. p. 2.

Publisher's Note Springer Nature remains neutral with regard to jurisdictional claims in published maps and institutional affiliations. 